\title{
The Analysis of English Translation of Chinese Trademark Words from the Perspective of Pragmatic Equivalence Theory
}

\author{
Jieli Cheng ${ }^{1, a}$, Shaohua Xie ${ }^{1, b}$ \\ Wuhan University of Science and Technology Address: 947 Heping Avenue, Qingshan District, \\ Wuhan, Hubei, P. R. China \\ aemail, ${ }^{\text {a email, }}$
}

Keywords: Chinese Trademarks, Pragmatic Equivalence Theory, Influencing Factors

\begin{abstract}
Trademarks are a sign that is used to mark the goods and is a distinction between other commodities and to increase the identification of goods. The World Intellectual Property Organization (WIPO) defines a trademark as: "A trademark is used to distinguish an industrial or commercial enterprise Or such a group of goods logo two "trademark is exclusive, subject to legal protection, and is also an intangible asset has two value This shows that the trademark in the market plays a role that can't be ignored.

With the global economic integration and China's accession to the WTO, China's large number of commodities exported to foreign countries, many domestic brands opened the way, in the international market occupies a place such as "Haier", "Moutai", "Lenovo" and other brands began to gradually Recognize the importance of trademark in stimulating consumption, opening the market, legal protection and so on, but also aware of the problems in the translation of trademarks and the severe challenges facing China's translation industry.

Therefore, this paper will analyze the influential factors of English translation of Chinese trademark to pragmatic equivalence from the principle of pragmatic equivalence, and then make the feasibility study. This paper's basic structure is firstly to introduce the pragmatic equivalence theory and basic knowledge of the trademark, and then based on the pragmatic equivalence theory to study the methods of English translation of Chinese trademark.
\end{abstract}

\section{Introduction: Introduction to Pragmatic Equivalence}

The famous American translator Eugene Nida proposed the theory of dynamic equivalence translation on the basis of the principle of equivalence. The innovation of this theory lies in the use of communicative theory to explain the process of translation, from the traditional original, the author And the target language reader into a dynamic perspective to view the message from the source language and the target language and the original reader and the recipient of the translation of the whole language of communication process Nida will be translated as: "the so-called Translation refers to the information from the semantics to the style (style) in the target language with the most recent, the most natural and equal language to reproduce the original language of the information which "closest" refers to the translation and the original meaning in the sense of as close as possible, "The most natural" refers to the translation should be as easy as the original text, read up catchy, without translation cavity, "with the most natural equivalents to reproduce the original language information" is Nida's core translation concept two It is important to emphasize that the absolute equivalence in translation is impossible, and it is only possible to be as close as possible. Therefore, the translation can't be applied, and it is not possible to literally translate words, And so on, that is, the translation of the reader's translation and feelings and the original reader's response to the original and the feelings are basically the same two but the function of peer-to-peer translation is not a traditional sense of the free translation of two Chinese and English two languages are completely different Of the language, in the form of structure and culture are very different, which is more deep in both Chinese and English language 
In order to achieve functional equivalence, we must have a comprehensive understanding of the cultural differences between the Chinese and English languages, which requires the translator not only to have a solid understanding of the cultural differences between the two languages. Translation of basic skills, but also to master the characteristics of different cultures, the two languages in the deep structure on the basis of the common, the original form of information on the reorganization of two as Nida once said: "For the real success of the translation, familiar with two Culture is even more important than mastering two languages. "In the specific operation of guiding translation practice, Nida has put forward a specific adjustment strategy, the greater the difference between the original language and the target language, the more the need for adjustment, Trademark translation, the translator needs to adjust the language of the trademark to meet the target language consumer's cultural context and psychological awareness, to achieve functional equivalence.

\section{Trademark and Its Translation Overview of Trademark}

Early 40 years ago, Larry Light, the famous advertisement expert in America, came up with the future marketing competition is the brand competition, which is to obtain the leading position for a brand. The future enterprise and investors will regard the brand as the most valuable assets. The market is more important than having a business, and the only way to have the market is to have the brand with leading position of the market .The core of brand is the trademark, and the trademark is the product of the commodity economy, in a time of the commodity economy highly development , trademarks' functions are becoming more and more significant, which relates directly to the efficiency of enterprises and the competitiveness of their products, and can promote the development of commodity economy orderly and healthily.

Definition of Trademark. Trademark is a sign that distinguishes an enterprise's goods or services from other businesses' goods or services. In other words, a trademark is a specific mark on a commodity or service that is used by the consumer to identify or confirm the production operator and service provider of the goods and services. This basic definition shows the essential attributes and main features of the mark. And only on this basis, in different forms to define the trademark, and to build a trademark legal system to determine its specific content.

In the Chinese Trademark Law, the definition of a trademark is "any visual mark that distinguishes the goods of natural persons, legal persons or other organizations from the goods of others, including words, figures, letters, numbers, three-dimensional signs and Color combinations, and combinations of the above elements ". This definition indicates that the mark is a sign that is used for merchandise and is distinguished, and in contemporary it is a visual sign. The definition of trademark in Chinese trademark law is accurate, revealing the essential characteristics of trademark.

Functions of Trademark. Today, people almost everywhere can access to trademarks, trademarks into a lot of people's minds. Trademarks have a wide range of functions, there are a variety of functions can't be ignored, mainly in:

Identify the function of the source of goods

Or that the trademark has a recognition, which is the basic function of the trademark, the primary function, the trademark is to identify the source of goods to be able to produce, so this function can become a trademark, no such function can not be called a trademark. Trademark identification as a basic function, by its extension, the trademark there are a number of links associated with the function.

Promote the Function of Sales. Production operators use the trademark to mark the source of the goods, consumers through the trademark to distinguish the same kind of goods, understand the goods, make a choice, so that the trademark to open up the market, an important tool in the market to compete, this is another important function of the trademark The

Ensure the Quality of Goods Function. The producer provides the goods by means of the mark, and the service provider indicates that a service is provided by the trademark, and the consumer also 
identifies the goods or services through the mark and identifies the quality of the goods. This identification relates to the production and operation the rise and fall of the use of the trademark to promote the production and operation focus on quality and maintain the quality of stability. In reality, the brand down, the whole enterprise is difficult to follow the phenomenon when there. Therefore, the use of trademarks can make the production operators to experience the pressure of market competition, and concerned about the quality of goods, trademarks and thus played a role in ensuring the quality of goods. Of course, this guarantee is a trademark through the production operators and consumers linked to a specific relationship.

\section{Discussion: Chinese Trademark Translation Based on Pragmatic Equivalence}

Influencing Factors of Trademark Translation. As a type of intercultural communication activity, trademark translation links up with linguistic knowledge, cultural psychology and aesthetic standards and it has attracted many scholars to conduct comprehensive studies. This paper will introduce the factors influencing trademark translation from two aspects.

Linguistic Factor: Both English and Chinese trademarks are very short, and this trademark is easy to be remembered by consumers, to a certain extent, can also stimulate consumer interest. But the Chinese trademark and the English trademark or even a lot of different places, the specific differences are as follows:

Most of the English trademarks use the abbreviation or full name of the personal name as a trademark, such as Ford Motor Company's trademark is the founder Henry Ford's name. Chinese brands often use names as trademarks, such as "Phoenix" bicycles, "Qingdao" beer and so on.

English trademarks in the syllable composition without any restrictions and requirements, not less than 1-2 syllables, up to five or more syllables, showing greater arbitrariness, such as: Kent (cigarettes), Nike (sneakers) ; And most Chinese trademarks by two syllables, such as: "Haier", "Li Bai" and so on.

In general, the trademark and its attributes have three relationships: zero, direct and indirect. The relationship between the English mark and the product attribute is basically any of the three relationships described above, but the zero relationship is the majority, such as "joy" (the name of the cleaning product), which means "happy". Although the relationship between most Chinese trademarks and product attributes is indirect, such as "clean products", this can give us an immediate "clean" impression that stimulates people's desire to buy.

Cultural Factor: Culture is carried by language and propagated, and language is an integral part of culture. Different peoples have different cultures, because of the different cultures, the same kind of things in different cultures have different meanings. A popular thing in a culture

Material, in another culture may be a taboo thing. Such as the well-known brand "Wu yang" (Five Rams), the brand name of the "sheep" should not use goats, the word in the English culture, "satyr" meaning. It can be seen that the translation of trademark words is a kind of special translation, and the handling of cultural factors plays a decisive role in the process of trademark translation. As we all know, the function of the trademark is not only to provide information to the consumer, but also to better demonstrate the value and characteristics of the product, so as to gain a competitive advantage in the market. Moreover, the translation of trademark words is not only the corresponding conversion of the meaning of meaning, more importantly, to achieve its associative meaning and symbolic conversion, in order to achieve pragmatic equivalence.

The translation should take into account the cultural characteristics of the different commodities, reflect the national characteristics of the goods, respect the national feelings of the target market consumer groups, and grasp the associative meaning, so that the translation of the trademark words can cause the nation's psychological identity, in the target culture Beautiful association. Therefore, in the translation of the trademark brand should take into account the cultural differences, if necessary, to the trademark brand translation of the appropriate treatment. 
Common Methods of Trademark Translation. The translation of the Chinese trademark should reflect the unique culture of the Chinese trademark. At the same time, after the translation of the trademark should be translated into the reader on the trademark and the reader has a similar reaction and feel similar to the two, but because of the huge differences between Chinese and foreign cultures, some trademarks may be literal translation of the original meaning or even produce counterproductive effect of two It is necessary to translator in the translation of the trademark at the same time fully understand the local cultural characteristics, consumer aesthetic psychology, habits and preferences two also have to avoid some of the culture in the derogatory taboo, in order to achieve stimulating consumption, open up the target market target.

Transliteration: Transliteration is the original language pronunciation translated into the target language similar or the same pronunciation, can be divided into pure tone transliteration and partial tone transliteration.

Pure tone, also known as direct transliteration, according to foreign trademark English pronunciation, selection and similar to the Chinese pronunciation of Chinese characters for translation. This method has the effect of maintaining the beauty of the original trademark. Such as "Motorola Motorola" (cell phone), "Sony Sony" (TV), "Kodak" (photo).

Part of the tone is able to stimulate the consumer's imagination for the trademark. There are many homonyms in the Chinese language, so the use of this method to translate can stimulate the concept of trademark beauty. Such as "Arche", translated as " Arche " and "Pantene", translated as " Pantene ", to maintain the original syllable of the celebration and "Qian" choice, "Ting" show the characteristics of cosmetics products.

Literal Translation: When the meaning of the original mark after the translation of the word and the target trademark culture harmony, you can use the text translation. The translation of this Chinese trademark is everywhere. For example, "bee flower, honey bee flower" (conditioner) means that people who use the product will be as happy as flowers, translating the original voice and semantic beauty, which conforms to Eastern and Western cultural ideas and logical thinking.

Combination of Transliteration and Literal Translation: The best translation technique is to combine English translation with free translation. It is very difficult to find a trademark that conforms to a similar translation method. Because the number is not a lot, after careful looking week we found "gold to" to meet this translation skills. English name is called " Goldlion " (Golden Lion literal translation), in Western countries, especially in the UK, "lion" greatly accurately marked the male muscle and erection. So, as a person's brand, "Goldlion" has a considerable sales in the world.

\section{Notices for Chinese Trademark Translation}

Along with the development of the trademark, the folk culture, the customs and habits, the diversity of language of different countries, lead to the use of the trademarks in one country not to be accepted by another country. In consideration of tremendous difference between the Chinese and western culture in language habits, cultural customs and so on, there will be inevitably be improper translation of words in the process of translating, which will become a big obstacle that blocks our goods into the world market . So in the English translation of Chinese trademark, the following points should be paid attention to.

Simplicity and Proper Words Usage

Only the trademark translation is simple and concise, easy to understand, easy to remember, can cause the consumer's resonance, to their left a deep impression. Specific to the free translation of the trademark, the need to use the correct words, it is because the free translation of the trademark is usually meaningful words and phrases, and contains the business hope of the use of the product effect. "FLYING PIGEON" is the English translation of the "Flying Pigeon" electric bike. "Pigeon" is a small and fragile bird, used for hunting, and pigeons are usually used as a symbol of peace, also 
refers to the peace of love, therefore, if translated as "Feifei pigeons", it is more likely to let A person produces a fine association of "travel, spreading peace messages", which not only reflects the characteristics of the product, but also expresses good wishes.

Proper Conveyance of the Implicature: We should pay attention to the language characteristics, folk tradition and culture background of the target language's market and so on, or you will make matters worse. Such as "Jin Ji” alarm clock (gold cock), “cock” in English also refers to the penis, which is not a polite language, such English translation would give people the impression of language impoliteness, and lack of cultivation, to damage the product's and the enterprise's image; "Bai Ling” pen (white feather) goes unattended in English-speaking countries, the reason is that in English, "to show the white feather" symbols coward. So we must pay attention to the expression of the implicit meaning when translating the Chinese trademarks into English.

Compliance with Product Features: Chinese trademarks often use Chinese ancient proverbs to express the company's good wishes for development. But there are many companies use pinyin, but this method will make the company's brand to lose a more profound meaning, is not conducive to their trade to the world. Such as "HENG-SHUN", "WENSLI", "Xiy-ingmen", these English translations can't reflect the positive meaning of the original Chinese trademark. In the process of trademark translation, in order to meet the characteristics of goods, we must first grasp the characteristics of goods, get a lot of understanding, as a trademark of the premise of accurate translation.

\section{Conclusion}

This paper tries to break through the traditional study of trademark translation and discusses how to reach translation equivalence from the perspective of pragmatics. In addition to the English translation of the bilingual trademark follow their own translation principles and laws, we must also focus on the study of cultural factors related to the two languages, in particular, the language of the country into the language of the two translation of the success of the trademark has played a very critical The two strategies of Chinese translation of the Chinese trademark is only the relative classification of the author's summary, not to say that there is no other translation of the two as long as consumers can bring refreshing feelings, to open the product sales play a role in fueling.

Then it is a successful translation of two examples of the above argument can be seen that trademark translation is a dynamic symbol conversion activities, which is part of cross-cultural communication, functional equivalence theory applied to trademark translation and has a guiding significance of two translators functional equivalence theory under the guidance of a flexible use of various translation strategies and techniques, the goods contained in the cultural connotation of expression, across cultural barriers to achieve cultural complementarity, so as to maximize the desire to stimulate consumers to buy goods for the Chinese market, promote the process of internationalization of goods to add a force.

\section{References}

[1] Austin, J. L. How to Do Things With Words[M ].Oxford: Oxford University Press, 1980 (1962).

[2] Baker,Mona. In Other Words: A Coursebook on Translation[M].Beijing: Foreign Language Teaching and Research Press,2000.

[3] Hickey Leo. The Pragmatics of Translation[M].Shanghai: Shanghai Foreign Language Education Press,2001.

[4] Levinson S.C.Pragmatics[M].Beijing: Foreign Language Teaching and Research Press,2001.

[5] Nida E. A. Language, Culture, and Translating[M].Shanghai: Shanghai Foreign Language Education Press, 1993.

[6] Chaofeng Ding . On Strategies of Trademark Translation [J].Overseas English,2011(7).

[7] Ziran He. Introduction of Pragmatics [M ].Changsha: Hunan Education Publishing Press,1988. 
[8] Ping Lv. A Brief Remark on Translating Trade Marks [J]. Journal Beijing International Studies University,2000(6):42.

[9]Zhuoli Sheng. Pragmatic Equivalence in Translation [J]. Journal of Zunyi Normal College,2006(1):45-47.

[10]Ying Wang. Chinese-Western Cultural Differences and Trademarks Translation [J]. Sci-tech Information of Heilongjiang Province, 2008(3):140. 